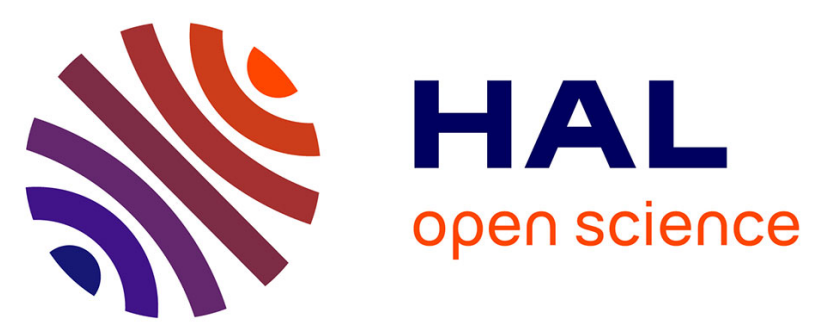

\title{
Fabrication and Electrochemical Properties of Three-Dimensional (3D) Porous Graphitic and Graphenelike Electrodes Obtained by Low-Cost Direct Laser Writing Methods
}

Micheal Burke, Cathal Larrigy, Eoghan Vaughan, George Paterakis, Labrini

Sygellou, Aidan Quinn, Grégoire Herzog, Costas Galiotis, Daniela Iacopino

\section{To cite this version:}

Micheal Burke, Cathal Larrigy, Eoghan Vaughan, George Paterakis, Labrini Sygellou, et al.. Fabrication and Electrochemical Properties of Three-Dimensional (3D) Porous Graphitic and Graphenelike Electrodes Obtained by Low-Cost Direct Laser Writing Methods. ACS Omega, 2020, 5, pp.1540 1548. 10.1021/acsomega.9b03418 . hal-02440796

\section{HAL Id: hal-02440796 \\ https://hal.univ-lorraine.fr/hal-02440796}

Submitted on 2 Dec 2020

HAL is a multi-disciplinary open access archive for the deposit and dissemination of scientific research documents, whether they are published or not. The documents may come from teaching and research institutions in France or abroad, or from public or private research centers.
L'archive ouverte pluridisciplinaire HAL, est destinée au dépôt et à la diffusion de documents scientifiques de niveau recherche, publiés ou non, émanant des établissements d'enseignement et de recherche français ou étrangers, des laboratoires publics ou privés. 


\section{Fabrication and Electrochemical Properties of Three-Dimensional (3D) Porous Graphitic and Graphenelike Electrodes Obtained by Low-Cost Direct Laser Writing Methods}

Micheal Burke, Cathal Larrigy, Eoghan Vaughan, George Paterakis, Labrini Sygellou, Aidan J. Quinn, Grégoire Herzog, Costas Galiotis, and Daniela Iacopino*

Cite This: ACS Omega 2020, 5, 1540-1548

Read Online

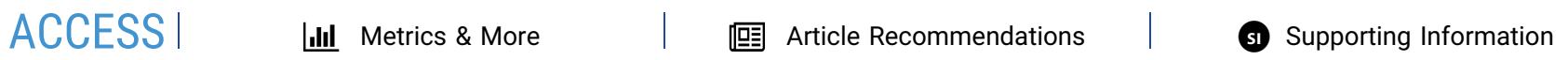

ABSTRACT: The development of three-dimensional (3D) porous graphitic structures is of great interest for electrochemical sensing applications as they can support fast charge transfer and mass transport through their extended, large surface area networks. In this work, we present the facile fabrication of conductive and porous graphitic electrodes by direct laser writing techniques. Irradiation of commercial polyimide sheets (Kapton tape) was performed using a low-cost laser engraving machine with visible excitation wavelength $(405 \mathrm{~nm})$ at low power $(500 \mathrm{~mW})$, leading

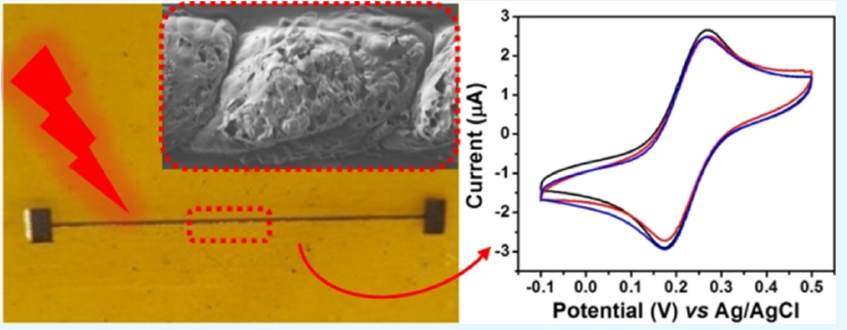
to formation of 3D laser-induced graphene (LIG) structures. Systematic correlation between applied laser dwell time per pixel ("dwell time") and morphological/structural properties of fabricated electrodes showed that conductive and highly $3 \mathrm{D}$ porous structures with spectral signatures of nanocrystalline graphitic carbon materials were obtained at laser dwell times between 20 and $110 \mathrm{~ms} /$ pix, with graphenelike carbon produced at $50 \mathrm{~ms} / \mathrm{pix}$ dwell time, with comparable properties to LIG obtained with high cost $\mathrm{CO}_{2}$ lasers. Electrochemical characterization with inner and outer sphere mediators showed fast electron transfer rates, comparable to previously reported 2D/3D graphene-based materials and other graphitic carbon electrodes. This work opens the way to the facile fabrication of low-cost, disposable electrochemical sensor platforms for decentralized assays.

\section{INTRODUCTION}

Graphitic and graphenelike materials are intensively studied because of their unique physical and chemical properties which can be exploited for fabrication of electrochemical sensors and biosensors. $^{1-3}$ The interest toward these materials for sensing applications arises from the possibility of tuning their analytical performance by controlling structure, morphology, porosity, and surface functionalities of the carbon electrodes, as all the above chemico-physical parameters have a direct impact on the electron transfer (ET) rate. For example, it is known that graphite basal and edge planes possess different surface morphologies and that ET kinetics are greatly enhanced at graphene edge sites because of high density of defects and corrugations. ${ }^{1}$ Moreover, it has been reported that the use of porous graphene three dimensional (3D) structures can lead to enhanced electrochemical responses, associated with availability of highly conducting pathways, providing high mass transport and charge transfer rates. ${ }^{4,5}$ Therefore, the realization of high-performance electrochemical sensors requires the availability of large mass two-dimensional (2D) graphitic materials extending into large porous 3D networks. This process is usually achieved by application of costly (chemical vapor deposition, CVD), ${ }^{6}$ cumbersome (spray coating), ${ }^{7}$ or inefficient (self-assembly of reduced graphene oxide) techni- ques. $^{8}$ Another issue is that the complex solution processing of graphenelike materials leads to aggregated graphene sheets with dramatically reduced surface area and, therefore, reduced electrochemical activity. ${ }^{9}$ Therefore, the development of straightforward fabrication methods enabling high-throughput, low-cost, and large-scale fabrication of 3D graphene-based electrodes under ambient conditions is a technologically important goal for the realization of highly sensitive electrochemical sensors. Recently, porous graphitic structures have been obtained by direct laser writing methods on commercial polyimide sheets (Kapton tape). For example, extended 3D graphitic structures (laser-induced graphene, LIG) were patterned on polyimide by simple direct writing with $\mathrm{CO}_{2}$ laser irradiation under ambient conditions. ${ }^{10-13}$ The formation of LIG was ascribed to the generation of local high temperatures induced by a resonance effect between the laser wavelength and the polyimide, which caused carbonization and subsequent graphitization of polyimide. During this process,

Received: October 14, 2019

Accepted: December 18, 2019

Published: January 10, 2020 
the polyimide $\mathrm{sp}^{3}$-carbon atoms were photoconverted in $\mathrm{sp}^{2}$ carbon atoms by pulsed laser irradiation. Atoms from broken $\mathrm{C}-\mathrm{H}, \mathrm{C}-\mathrm{O}, \mathrm{C}=\mathrm{O}$, and $\mathrm{C}-\mathrm{N}$ bonds were released as gas, thus contributing to porous structure formation. In addition, as the process occurred under ambient conditions, the fast release of locally available, hydrogen, oxygen, and water in the form of $\mathrm{H}_{2}, \mathrm{CO}$, and $\mathrm{CO}_{2}$ gases resulted in formation of highly porous structures. ${ }^{10}$ The main application of LIG materials so far has been in the field of energy storage, whereby LIG structures were successfully used as electrodes for fabrication of low cost and flexible supercapacitors. ${ }^{10-12}$ However, recent reports of LIG electrodes for demonstration of on-chip electrochemical sensing have also emerged. ${ }^{14,15}$ For example, Nakak et al. found that the morphology of LIG, rich in defect and edge plane sites and functional enough to be wetted by aqueous electrolytes, was particularly amenable to electrochemical sensing applications and reported high electro-catalytic activity and high sensitivity toward ascorbic acid, dopamine, and uric acid. ${ }^{14}$ The same authors also demonstrated sensitive (5 pM in serum) biodetection by aptamer biofunctionalization of LIG. ${ }^{16}$ Also, Cardoso et al. showed fabrication of molecularly imprinted chloramphenicol sensors on LIG electrodes. ${ }^{17}$ The variety of applications and the simplicity of instrumentation (laser engraving machine operating under ambient conditions) and precursor materials (commercial Kapton tape) required to make such electrodes suggest that LIG could be used for the large-scale fabrication of disposable electrochemical sensors for decentralized assays (point-of-care, in situ monitoring). Toward this end, LIG structures were recently obtained by the use of visible laser sources and demonstration of biogenic amines in food samples achieved. ${ }^{18-20}$ This is a desirable development toward further reduction of production costs. However, the use of $405 \mathrm{~nm}$ lasers required pre-electrode or postelectrode doping in order to show satisfactory applications.

In this paper, we present the fabrication of porous, conductive, and 3D graphitic electrodes obtained by direct writing of polyimide sheets under ambient conditions with a low-cost laser engraving tool equipped with a $405 \mathrm{~nm}$ irradiation wavelength laser diode. As the irradiation power of this laser source was fixed at $500 \mathrm{~mW}$, a detailed investigation of the correlation between applied dwell times and the resulting morphological, structural, electrical, and electrochemical characteristics of obtained LIG electrodes was performed. It was found that dwell times in the range 40-60 $\mathrm{ms} / \mathrm{pix}$ led to formation of conductive, porous structures with nanocrystalline graphitic carbon spectral signatures, evidenced by Raman and X-ray photoelectron spectroscopy (XPS) data. The electrochemical properties of LIG electrodes were tested with innersphere and outersphere redox mediators and showed fast ET kinetics and heterogeneous electron transfer (HET) rates comparable to other graphene-based materials and edge plane pyrolytic graphite (EPPG).

\section{RESULTS AND DISCUSSION}

All electrodes in this work were fabricated by direct laser writing of polyimide tape attached onto a glass microscope slide or coverslip for mechanical support. Figure 1a shows a schematic of the LIG process, whereby computer-aided designs were written on polyimide tape by laser raster scanning with a commercial laser engraving machine. Figure $1 \mathrm{~b}-\mathrm{d}$ shows photographs of representative one-, two-, and three-electrode electrochemical sensor platforms fabricated at $50 \mathrm{~ms} /$ pix dwell time, comprising a thin line (ca. $120 \mu$ m width) as the working
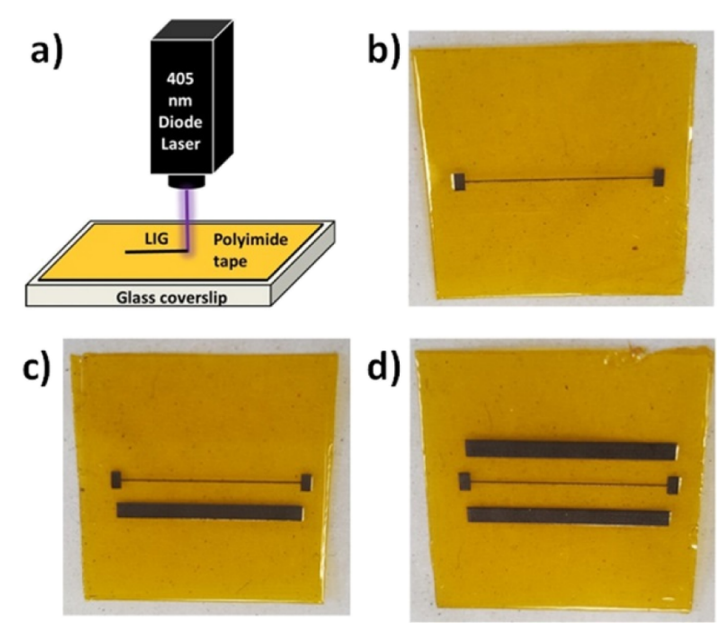

Figure 1. (a) Schematic of the LIG fabrication process; (b-d) photographs of LIG electrochemical platforms showing working (thin line, $\sim 120 \mu \mathrm{m}$ width) and counter/reference electrodes (thick lines, $\sim 1 \mathrm{~mm}$ width) fabricated at $50 \mathrm{~ms} /$ pix dwell time. Free domain photograph courtesy of author Eoghan Vaughan.

electrode and thicker lines (ca. $1 \mathrm{~mm}$ ) as counter and reference electrodes.

Figure 2 shows correlated optical $(\mathrm{a}-\mathrm{d})$ and scanning electron $(\mathrm{e}-\mathrm{h})$ microscopy images of LIG electrodes obtained at representative $20,50,80$, and $110 \mathrm{~ms} /$ pix laser dwell times. It should be specified that the dwell time is the time the focused laser beam rested on a single pixel and illuminated it. Therefore, longer pixel times correspond to lower laser scan speeds. Complete sequences of optical and electron microscopy images for the full range of dwell times $(10-110 \mathrm{~ms} / \mathrm{pix})$ are shown (Figures $\mathrm{S} 1$ and S2, respectively). The optical images showed that the LIG track patterns comprised individual quasi-hemispherical islands (see blue square Figure 2c), where each island corresponded to one pixel in the original design. At low dwell times, the LIG pixel islands had a diameter of ca. $100 \mu \mathrm{m}$ with clear "necks" between adjacent islands. However, as the dwell time increased, the island diameters increased to $\sim 130 \mu \mathrm{m}$, and the interisland separation decreased until coalescence of adjacent pixel islands was observed above $40 \mathrm{~ms} /$ pix dwell time. Scanning electron microscopy (SEM) images showed that the LIG islands were characterized by a highly porous $3 \mathrm{D}$ morphology associated with the rapid generation of gas (breaking of $\mathrm{C}-\mathrm{H}, \mathrm{C}-\mathrm{N}, \mathrm{C}-$ $\mathrm{O}, \mathrm{C}=\mathrm{O}$ atoms, and local oxygen) occurring during the LIG process and increased by the availability of local $\mathrm{O}_{2}$ because of the process being performed under ambient conditions. ${ }^{10,21}$ As already observed in the optical images, SEM images showed that individual islands became increasingly better-defined and showed increased coalescence as the dwell time increased. Specifically, at $20 \mathrm{~ms} /$ pix dwell time, a 3D surface topography characterized by micron-scale blister-like features was observed. Very few micropores were observed at this dwell time. In contrast, as the laser dwell time increased, open micropores were clearly evident across the surface, consistent with "bursting" of the microblisters due to explosion of gas microbubbles and/or ablation of surface material. This morphology was consistent with the occurring of a laserassisted high-temperature and high pressure process, whereby polyimide absorbed the laser photon energy and converted it into heat. ${ }^{22}$ In order to quantify the sample porosity, gas 

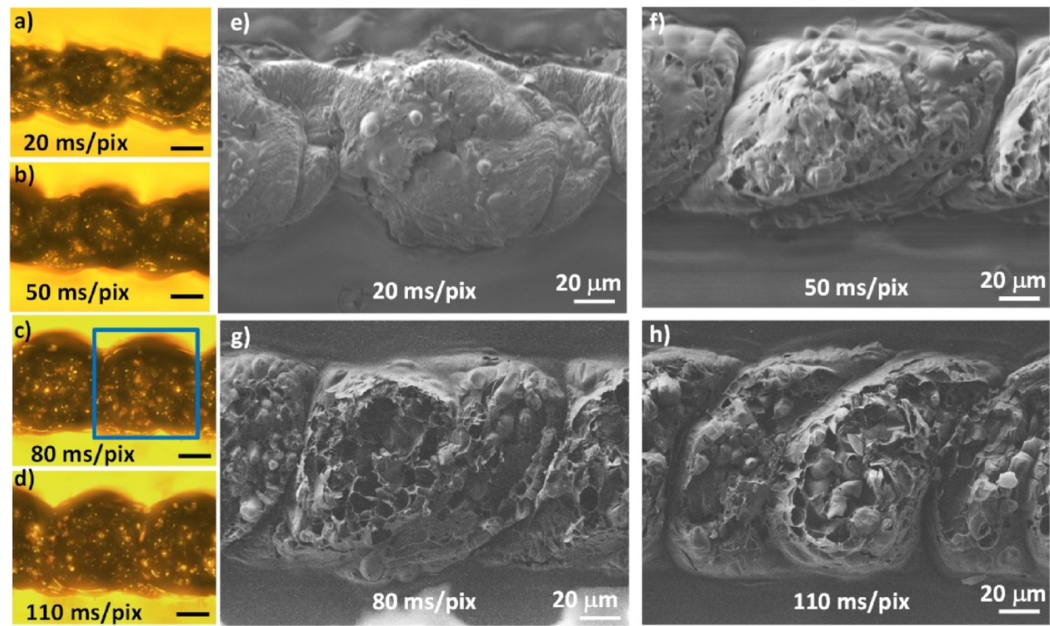

Figure 2. Optical $(\mathrm{a}-\mathrm{d})$ and electron $(\mathrm{e}-\mathrm{h})$ microscopy images of LIG electrodes fabricated at 20, 50, 80, and $110 \mathrm{~ms} /$ pix dwell times. Scale bars on optical images: $50 \mu \mathrm{m}$.

adsorption measurements (Figure S3) were performed for 50 $\mathrm{ms} / \mathrm{pix}$ LIG and revealed formation of a microporous structure with a specific surface area of $428 \mathrm{~m}^{2} / \mathrm{g}$, higher than the 342 $\mathrm{m}^{2} / \mathrm{g}$ value, reported by Lin et al., for LIG structures obtained by $\mathrm{CO}_{2}$ laser irradiation. ${ }^{10}$

Electron microscopy was also used to measure the thickness of fabricated LIGs. The nominal thickness of commercial polyimide tape was $80 \mu \mathrm{m}$. Figure 3a shows a cross-section

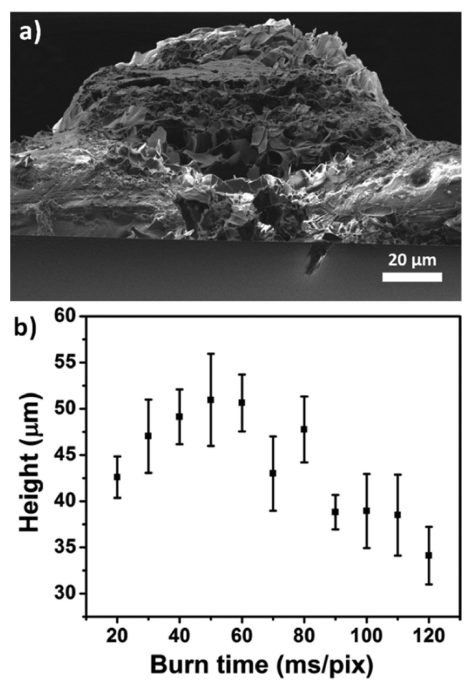

Figure 3. (a) Cross-section SEM image of an LIG track written at 50 $\mathrm{ms} / \mathrm{pix}$; (b) profilometer height measurements for LIG tracks in the $20-120 \mathrm{~ms} / \mathrm{pix}$ dwell time range.

SEM image of a single line written at dwell time $50 \mathrm{~ms} / \mathrm{pix}$ and showing a LIG structure $\sim 50 \mu \mathrm{m}$ protruding $\sim 50 \mu \mathrm{m}$ above the polyimide substrate. The nearly Gaussian LIG shape reflected the laser intensity beam distribution, a feature that has not been reported with higher cost/high power laser engraving systems. ${ }^{23}$ Thickness data for LIG lines written in the $20-120 \mathrm{~ms} /$ pix dwell time range were obtained by profilometry. Figure $3 \mathrm{~b}$ shows average heights measured for three different sets of lines across three areas. The protrusion thickness increased from 43 to $51 \mu \mathrm{m}$ as dwell times increased from 20 to $50 \mathrm{~ms} / \mathrm{pix}$ and slowly decreased to $34 \mu \mathrm{m}$ for higher dwell times, suggesting the occurrence of oxidation or ablation processes, deleterious for the formation of good quality graphitic carbon structures. ${ }^{10}$

LIG surface properties investigated by contact angle (CA) measurements showed hydrophobic characteristics. Specifically, measurements were performed for LIG structures obtained in the $20-110 \mathrm{~ms} /$ pix dwell times (see Figure S4), and the following CA values were found: LIG $20 \mathrm{~ms} / \mathrm{pix}=85^{\circ}$; LIG $50 \mathrm{~ms} / \mathrm{pix}=94^{\circ}$; LIG $80 \mathrm{~ms} / \mathrm{pix}=146^{\circ}$; and LIG 110 $\mathrm{ms} / \mathrm{pix}=128^{\circ}$. These data were in contrast with LIG hydrophobic properties reported for structures made by $\mathrm{CO}_{2}$ laser scribing. ${ }^{14,24}$ However, our data were in agreement with surface properties of other LIG structures fabricated by 405 nm lasers ${ }^{18,19}$ The CAs of low dwell time structures were consistent with CA values reported for amorphous carbon (aC) structures deposited under either high temperature (200 $\left.{ }^{\circ} \mathrm{C}, \mathrm{CA}=97^{\circ}\right)^{25}$ or high temperature/pressure $\left(85^{\circ} \mathrm{C}\right.$ and 10 mbar, $\mathrm{CA}=85^{\circ}$ ) conditions. $^{26}$ The hydrophobicity of a-C materials was attributed to the presence of nanosized to microsized particles randomly distributed on the carbon surface. Similarly, a microporous surface was observed in LIG structures obtained at 20 and $50 \mathrm{~ms} /$ pix dwell times. Reported values were also in agreement with wettability studies performed on graphitic carbon, reporting apparent watercontact angles between 35 and $126^{\circ}$ for either basal or edge graphite surfaces, depending on surface contamination and roughness. ${ }^{27}$ The increased hydrophobicity measured for the $80 \mathrm{~ms} /$ pix LIG structure could be ascribed to an increased surface roughness and by the presence of oxygen and other reactive molecules free to attach to dangling bonds during LIG formation. In addition, as LIG formation occurs under ambient conditions, air molecules can easily get trapped within the microporous structures, preventing liquid molecules to enter into the pores and, therefore, giving hydrophobicity. A slight decrease in hydrophobicity (from 146 to $128^{\circ}$ ) was measured for LIG structures obtained at $110 \mathrm{~ms} /$ pix and was associated with the occurrence of oxidation and ablation processes, resulting in an increased percentage of $\mathrm{sp}^{3}$ bonds (see further Raman and XPS characterization). ${ }^{25,26}$

Figure 4 shows electrical characterization data acquired from a total of 57 transmission line structures fabricated over a range of dwell times (10-120 ms/pix). Figure 4a shows a typical set of two-terminal current versus voltage $(I-V)$ curves for positive bias voltages $(0-1 \mathrm{~V})$, measured for a single 

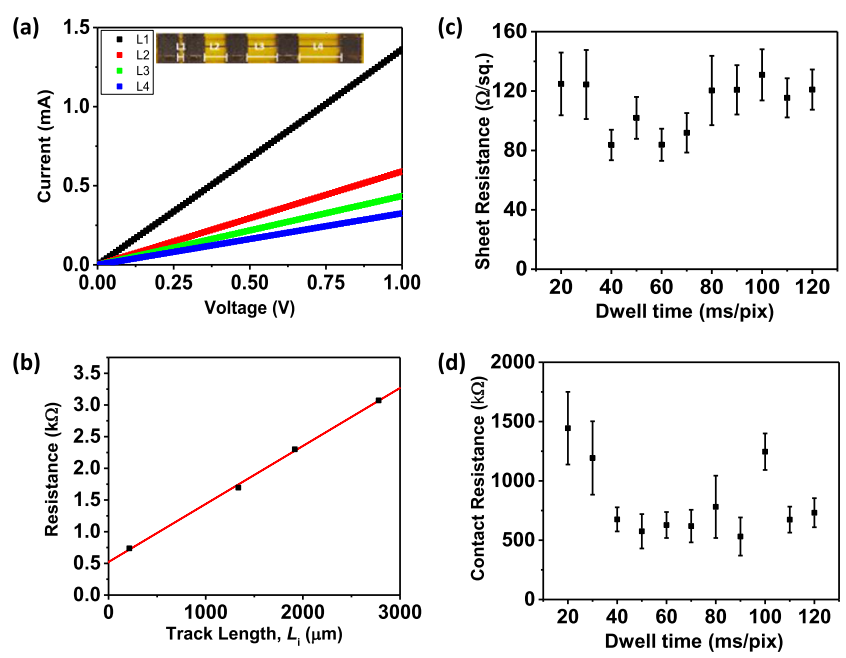

Figure 4. (a) $I-V$ measurements on a transmission line measurement (TLM) structure written at $50 \mathrm{~ms} / \mathrm{pix}$ dwell time, comprising four different track lengths $\left(L_{\mathrm{i}}\right)$ with mm-scale contact pads. (b) Corresponding track resistance $\left(R_{\mathrm{i}}\right)$ values vs length $\left(L_{\mathrm{i}}\right)$. Inset: photograph of TLM structures; (c) sheet resistance vs dwell time, and (d) contact resistance vs dwell time measured for dwell times 10-120 $\mathrm{ms} / \mathrm{pix}$.

transmission line device fabricated at $50 \mathrm{~ms} /$ pix. All curves are linear over the bias voltage range $( \pm 1 \mathrm{~V})$. Figure $4 \mathrm{~b}$ shows the track resistance data for this structure plotted versus track length. Linear regression of these data allows the sheet resistance and the contact resistance to be calculated from the slope and intercept, respectively (see eq 1, Experimental Session). For this device, sheet resistance $R_{\mathrm{s}}=85 \pm 8 \Omega$ / square and contact resistance $R_{\mathrm{c}}=575 \pm 65 \Omega$ were measured. Panels $\mathrm{c}$ and $\mathrm{d}$ in Figure 4 show the extracted $R_{\mathrm{s}}$ and $R_{\mathrm{c}}$ data for multiple devices for each dwell time (30 devices in total). The trend shows a region of lower sheet resistance (80-100 $\Omega /$ square) for dwell times in the range $40-70 \mathrm{~ms} / \mathrm{pix}$. The contact resistance data (Figure $4 \mathrm{~d}$ ) also show minimum values $(\sim 600 \Omega)$ over the same dwell time range. These data correlated well with the small and not uniform pore distribution and poor degree of structural connection between pixels observed in the optical images of Figure 2 for low dwell times. However, for dwell times of $40 \mathrm{~ms} / \mathrm{pix}$ and above sheet resistance values abruptly dropped and saturated at $\sim 80 \Omega$ / square. This behavior was consistent with the formation of structures constituted by well-connected spherical units, as shown by optical and electron microscopy images (Figure 2). In addition, measured sheet resistance values correlated well with the observed thickness values previously measured, showing that up to $60 \mathrm{~ms} / \mathrm{pix}$, LIG structures of increased thickness showed decreased sheet resistance values and that increased resistance was measured at high dwell times, in agreement with the occurrence of deterioration processes at such high dwell times. The measured sheet resistance values at this modest laser power $(0.5 \mathrm{~W})$ were lower than values reported for other graphene-derived samples (graphene/PET $280 \Omega /$ sq; $^{28}$ graphene $/ \mathrm{SiO}_{2} 350 \Omega /$ square; $^{29}$ rGO/PET 226 $\Omega /$ square $)^{30}$ and $\mathrm{LIG} /$ polyimide structures, reported by Romero et al., for a $405 \mathrm{~nm}$ laser diode at $0.1 \mathrm{~W}$ power $\left(242,295 \Omega\right.$ /square). ${ }^{21}$ As expected, sheet resistance values were larger than the $35 \Omega$ /square value, reported by Tour et al., for LIG from $\mathrm{CO}_{2}$ laser irradiation at higher laser powers $(3.5 \mathrm{~W}) .{ }^{10}$ In addition, our sheet resistance values were significantly lower in comparison with values reported for 3D nanostructured graphene structures obtained by inkjet printing/laser irradiation processes $(10 \mathrm{M} \Omega / \mathrm{sq}$ before laser irradiation, $0.7 \mathrm{k} \Omega / \mathrm{sq}$ post laser irradiation). ${ }^{31}$

Figure 5a shows representative LIG Raman spectra for four distinct dwell times: 20, 50, 80, and $110 \mathrm{~ms} / \mathrm{pix}$. Each spectrum shows two strong and distinct peaks in the 1000$1800 \mathrm{~cm}^{-1}$ range: the $\mathrm{G}$ mode centered close to $1580 \mathrm{~cm}^{-1}$, assigned to in-plane bond stretching of pairs of $\mathrm{sp}^{2}$ carbon atoms and the $\mathrm{D}$ mode centered close to $1350 \mathrm{~cm}^{-1}$, assigned to a defect-activated radial breathing mode. ${ }^{32,33}$ Most of the spectra showed weak and/or broad features in the $2 \mathrm{D}$ region close to $2700 \mathrm{~cm}^{-1}$. However, spectra with clear second-order 2D peaks could be observed for low dwell times $(20-60 \mathrm{~ms} /$ pix), indicating generation of graphenelike carbon morpholo-
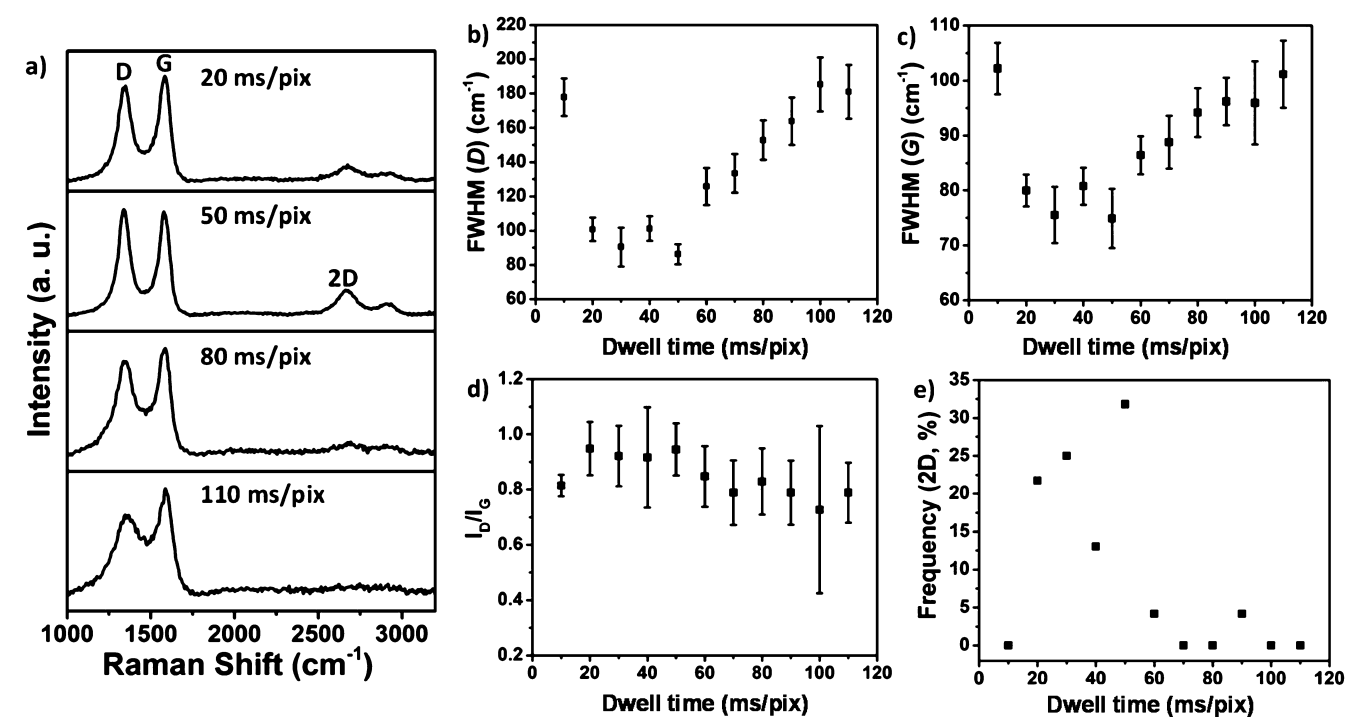

Figure 5. (a) Representative Raman spectra of LIG electrodes fabricated at 20, 50, 80, and $110 \mathrm{~ms} /$ pix dwell times; (b) fwhm intensity of the D peak vs dwell time; (c) fwhm intensity of the $G$ peak vs dwell time. Error bars in $(b, c)$ represent the standard error on the mean plus fit error; (d) $I_{\mathrm{D}} / I_{\mathrm{G}}$ ratios across dwell times; and (e) frequency of $2 \mathrm{D}$ peak vs dwell times. 
gies. As SEM images of Figure 2 showed formation of structures with inhomogeneous morphologies, a deeper Raman analysis was carried out, whereby for each dwell time, 24 spectra were acquired across an $8 \times 3$ grid with a pitch of 15 $\mu \mathrm{m}$ close to the central axis of the track, that is, over a rectangular area of length $120 \mu \mathrm{m}$ (parallel to track) and width $45 \mu \mathrm{m}$. Single Lorentzian line shapes were fitted to the D, G, and $2 \mathrm{D}$ regions. Considering the first-order $\mathrm{D}$ and $\mathrm{G}$ peaks, Figure $5 b, c$, respectively, showed that dwell times in the 20-50 $\mathrm{ms} /$ pix range yielded to the lowest mean full width at half maximum (fwhm) values of $85-100$ and $75-80 \mathrm{~cm}^{-1}$ for D and $\mathrm{G}$ peaks, respectively. For higher dwell times, a broadening of these peaks was observed, representative of an increased degree of disorder in the sample.

These observations fitted well with the trends reported by Koenig and Koenig in the first Raman study of graphite. ${ }^{34}$ On the basis of the studies of microcrystalline samples, the authors proposed an empirical model, whereby the ratio of the intensities for the $\mathrm{D}$ and $\mathrm{G}$ peaks $\left(I_{\mathrm{D}} / I_{\mathrm{G}}\right)$ scaled inversely with the crystallite size, $L_{a}$ (determined from X-ray data). In this work and subsequent reports from many groups, there is an evident trend of increased $I_{\mathrm{D}} / I_{\mathrm{G}}$ and broadening of both $\mathrm{D}$ and $\mathrm{G}$ peaks as the disorder in the sample increased, for example, through ion implantation of natural graphite. ${ }^{35}$ These authors more recently developed a model for disordered graphite with calculated disorder-induced peaks close to $1360 \mathrm{~cm}^{-1}$ (D peak) and $1620 \mathrm{~cm}^{-1}$ (now termed the $\mathrm{D}^{\prime}$ peak) and the expected G peak. ${ }^{33}$ Robertson and Ferrari developed a framework to interpret this "amorphization trajectory" from pure graphite to nanocrystalline graphite to amorphous carbon in terms of the factors that control the position, intensity, and widths of the $\mathrm{G}$ and $\mathrm{D}$ peaks. ${ }^{32}$ For LIG structures, data extracted from Lorentzian peak fits (Figures 5b,c and S5) are consistent with stage 1 of the trajectory, that is, between highly ordered graphite and nanocrystalline graphitic domains in a disordered carbon matrix. Specifically, the $G$ peak position (Pos $(\mathrm{G})$ ) remaining close to $1580 \mathrm{~cm}^{-1}$ (Figure S5b) and $I_{\mathrm{D}} /$ $I_{\mathrm{G}}<1$ (Figure $5 \mathrm{~d}$ ) across the entire dwell time range suggest that the laser-induced graphitization process results in nanocrystalline graphitic carbon films, with the highest order in the $20-50 \mathrm{~ms} / \mathrm{pix}$ dwell time range. Furthermore, comparing the spectra acquired for $50 \mathrm{~ms} /$ pix dwell time with the data reported by Lespade et al. suggests grain sizes in the range $3-7 \mathrm{~nm} .{ }^{35}$ The presence of sharp $2 \mathrm{D}$ peaks provides further evidence for a higher degree of ordering. Out of more than 250 spectra acquired across all dwell times, 23 spectra showed evidence of a distinct $2 \mathrm{D}$ peak fwhm $(2 \mathrm{D})<200 \mathrm{~cm}^{-1}$ and $I_{2 \mathrm{D}} / I_{\mathrm{G}}>0.2$, (Figure S5e). The majority of these spectra (21 of 23 ) were acquired in the $20-50 \mathrm{~ms} /$ pix dwell time range (Figure $5 \mathrm{c}$ ). Taken together, the Raman and $I-V$ data suggest an optimum dwell time window close to $50 \mathrm{~ms} /$ pix. Data for low dwell times (10-20 ms/pix) are consistent with a lower degree of order because of incomplete graphitization, while the data from the higher dwell times $(80-110 \mathrm{~ms} / \mathrm{pix})$ are consistent with disorder arising from unwanted oxidation or ablation.

The laser-treated films were further characterized by XPS. Figure 6 shows XPS surveys of LIGs obtained at 20, 50, 80, and $110 \mathrm{~ms} / \mathrm{pix}$, showing how the surface was mainly constituted by carbon, oxygen, and nitrogen. The deconvolution of the main $\mathrm{C}_{1 \mathrm{~s}}$ peak in its components (the main peak $\mathrm{C}-\mathrm{C} \mathrm{sp}{ }^{2}$ and $\mathrm{C}-\mathrm{C} \mathrm{sp^{3 }}$ carbon bonds, $\mathrm{C}-\mathrm{O}(\mathrm{H})$ epoxides and hydroxides, carbonyls $\mathrm{C}=\mathrm{O}$, and carboxyls $\mathrm{O}-\mathrm{C}=\mathrm{O}(\mathrm{H})$ and

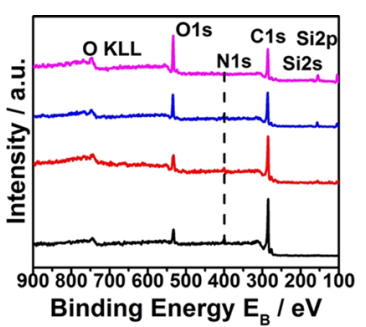

Figure 6. Survey scans of LIG electrodes fabricated at 20 (black line), 50 (red line), 80 (blue line), and 110 (pink line) ms/pix laser dwell times.

the $\pi-\pi^{*}$ transition loss) showed low contribution from polyimide $\mathrm{O}-\mathrm{C}=\mathrm{O}$ and $\mathrm{C}=\mathrm{O}$ bonds, whereas the contribution from $\mathrm{sp}^{2}-\mathrm{C}-\mathrm{C}$ bonds was the highest in the $20-80$ $\mathrm{ms} /$ pix dwell time interval. In contrast, at $110 \mathrm{~ms} / \mathrm{pix}$, the majority of carbon was $\mathrm{sp}^{3}$-type, supporting the previous hypothesis that deterioration of the surface or ablation occurred at this high dwell time. The $\mathrm{N}_{1 \mathrm{~s}}$ peak (shown in Figure S7) consists of one component at samples 20, 50, and $80 \mathrm{~ms} /$ pix centered at $400.1 \mathrm{eV}$, whereas in the $110 \mathrm{~ms} / \mathrm{pix}$ irradiated sample, a second component appeared at $\sim 402 \mathrm{eV}$, commonly assigned to oxidized nitrogen atoms. The atomic content of the constituent atoms is presented in Table 1. From the core level peaks of $\mathrm{C} 1 \mathrm{~s}, \mathrm{O} 1 \mathrm{~s}$, and $\mathrm{N} 1 \mathrm{~s}$, the percentage atomic concentration of carbon, oxygen, and nitrogen was determined by dividing the peak intensities with the appropriate relative sensitivity factor after correcting them from the experimentally determined EA10 analyzer transmission characteristics. High percentages of carbon $\mathrm{sp}^{2}$-type and low percentages of oxygen and nitrogen in the $20-80 \mathrm{~ms} /$ pix dwell time interval confirmed the rapid breaking and removal of $\mathrm{C}-\mathrm{N}, \mathrm{C}-\mathrm{O}$, and $\mathrm{C}=\mathrm{O}$ and $\mathrm{sp}^{2}$ carbon atoms occurring during the LIG process responsible for the formation of the porous morphology. Also, the $\mathrm{C}-\mathrm{O}$ peak becomes more prominent than the $\mathrm{C}=\mathrm{O}$ in the $20-50 \mathrm{~ms} /$ pix dwell time interval (Figure S6). In contrast, at $110 \mathrm{~ms} / \mathrm{pix}$, lower percentage of carbon $\mathrm{sp}^{2}$-type, increased presence of carbon $\mathrm{sp}^{3}$-type, and atomic oxygen atomic concentration occurs. Moreover, the presence of the nitrogen oxide component in the $\mathrm{N}$ 1s peak was detected under this burning condition.

Finally, the electrochemical behavior of LIG electrodes was investigated by cyclic voltammetry (CV) measurements performed with two redox systems: outer-sphere $\mathrm{Ru}$ $\left(\mathrm{NH}_{3}\right)_{6}{ }^{3+/ 2+}$ and inner sphere $\mathrm{Fe}(\mathrm{CN})_{6}{ }^{3-/ 4-}$. In order to accurately monitor the electrochemical behavior of the LIG working electrode and to accurately compare HET values with literature data, CVs were recorded in a three electrode system with a $\mathrm{Pt}$ wire as the counter electrode and $\mathrm{Ag} / \mathrm{AgCl}$ as the reference electrode. CVs were also recorded in $[\mathrm{Ru}-$ $\left.\left(\mathrm{NH}_{3}\right)_{6}\right]^{3+/ 2+}$ for systems including LIG as counter and working electrodes (see Figure S9) to show versatility and easiness of use of the fabricated systems. Quasi-reversible behavior between 5 and $500 \mathrm{mV} / \mathrm{s}$ scan rates and monotonic increase of the oxidation peak current with the square root of the scan rate was observed for both systems (Figure S9).

The electrochemical characteristics of LIG working electrodes fabricated between 20 and $110 \mathrm{~ms} / \mathrm{pix}$ are illustrated in Figure 7a. The electrodes showed decreasing values of differential peak potential $\left(\Delta E_{\mathrm{p}}\right)$ until a minimum value of 74.5 and $85.6 \mathrm{mV}$ was reached at $50 \mathrm{~ms} /$ pix for $[\mathrm{Ru}-$ $\left.\left(\mathrm{NH}_{3}\right)_{6}\right]^{3+/ 2+}$ and $\left[\mathrm{Fe}(\mathrm{CN})_{6}\right]^{3-/ 4-}$, respectively. The $\Delta E_{\mathrm{p}}$ value 
Table 1. Percentage $\mathrm{C}-\mathrm{C} \mathrm{sp}{ }^{2}, \mathrm{C}-\mathrm{C} \mathrm{sp}{ }^{3}$, Epoxides-Hydroxides, Carbonyls Carboxyls, and $\pi-\pi^{*}$ Bonding as Derived from $\mathrm{C} 1 \mathrm{~s}$ XPS Spectrum Deconvolution ${ }^{a}$

\begin{tabular}{|c|c|c|c|c|c|c|c|c|c|}
\hline sample (ms/pix) & $\% \mathrm{C}-\mathrm{C} \mathrm{sp}^{2}$ & $\% \mathrm{C}-\mathrm{C} \mathrm{sp}^{3}$ & $\% \mathrm{C}-\mathrm{O}(\mathrm{H})$ & $\% \mathrm{C}=\mathrm{O}$ & $\% \mathrm{C}-\mathrm{OOH}$ & $\% \pi-\pi^{*}$ & $\% \mathrm{C}$ & $\% \mathrm{O}$ & $\% \mathrm{~N}$ \\
\hline 20 & 56.8 & 13.6 & 15.4 & 6.6 & 3.7 & 3.9 & 88.1 & 6.2 & 5.7 \\
\hline 50 & 52.3 & 16.7 & 20.1 & 6.9 & 2.4 & 1.6 & 85.2 & 9 & 5.2 \\
\hline 80 & 60.2 & 19.4 & 13.8 & 3.2 & 2.1 & 1.3 & 84.2 & 10.8 & 5 \\
\hline 110 & 40.9 & 40.9 & 23.8 & 2.6 & 2.6 & 0 & 80 & 17.5 & 2.5 \\
\hline
\end{tabular}

${ }^{a}$ The $\%$ carbon, oxygen, and nitrogen atomic concentration is also presented for the $20,50,80$, and $110 \mathrm{~ms} /$ pix irradiated samples.
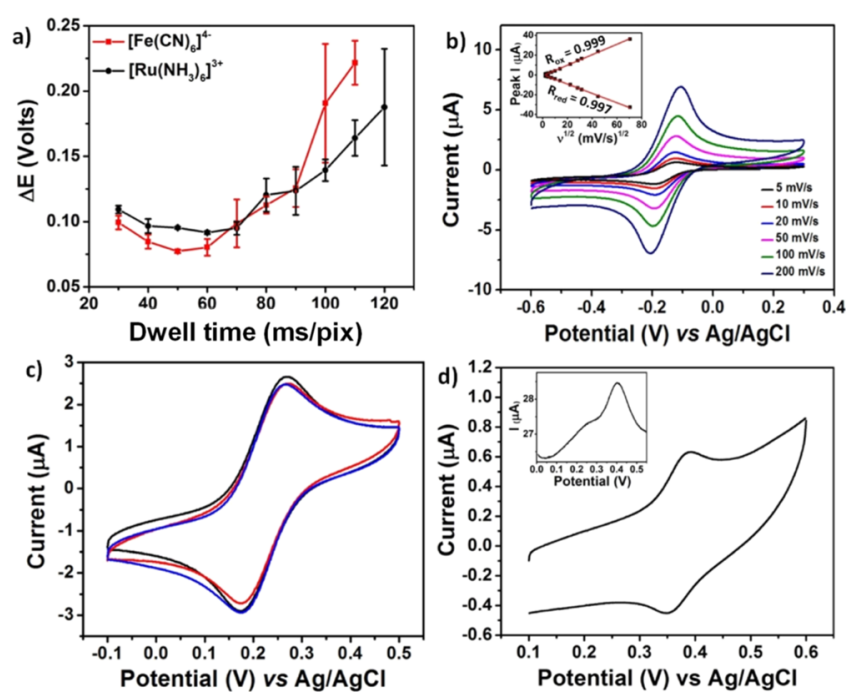

Figure 7. (a) $\Delta E_{\mathrm{p}}$ values recorded in the interval $20-120 \mathrm{~ms} /$ pix scan rate for $5 \mathrm{mM} \mathrm{Ru}\left(\mathrm{NH}_{3}\right)_{6}^{3+/ 2+}$ and $\mathrm{Fe}(\mathrm{CN})_{6}^{3-/ 4-}$ in $0.1 \mathrm{M} \mathrm{KCl}$ solution as the supporting electrolyte at $100 \mathrm{mV} / \mathrm{s}$; (b) cyclic voltammograms at LIG electrode $50 \mathrm{~ms} /$ pix at different scan rates in 5 $\mathrm{mM} \mathrm{Ru}\left(\mathrm{NH}_{3}\right)_{6}{ }^{3+/ 2+} 0.1 \mathrm{M} \mathrm{KCl}$. Inset: peak oxidation values versus square root of the potential scan rate; (c) repeat $\mathrm{CVs}$ at LIG electrode $50 \mathrm{~ms} /$ pix at $100 \mathrm{mV} / \mathrm{s}$ in $5 \mathrm{mM} \mathrm{Fe}(\mathrm{CN})_{6}^{3-/ 4-} 0.1 \mathrm{M} \mathrm{KCl}$; and (d) $\mathrm{CV}$ of $0.5 \mathrm{mM}$ benzocaine at the LIG electrode $50 \mathrm{~ms} / \mathrm{pix}$ in $0.1 \mathrm{M}$ $\mathrm{KCl}$ at $100 \mathrm{mV} / \mathrm{s}, \mathrm{pH}=2$. Inset: benzocaine square wave voltammetric response measured for the same electrode.

obtained for $\left[\mathrm{Ru}\left(\mathrm{NH}_{3}\right)_{6}\right]^{3+/ 2+}$ was lower than the average 85.6 $\mathrm{mV}$ value, reported by Nayak et al., for LIG structures obtained by $\mathrm{CO}_{2}$ laser fabrication and was comparable with the average $74.5 \mathrm{mV}$ value reported by the same authors for hybrid LIG/Pt electrodes. ${ }^{14}$ In contrast, the value obtained for $[\mathrm{Fe}-$ $\left.(\mathrm{CN})_{6}\right]^{3-/ 4-}$ was comparable with the average value of 85.6 $\mathrm{mV}$, reported by Nayak et al., for LIG electrodes. Figure $7 \mathrm{~b}$ shows CVs of an LIG working electrode fabricated at $50 \mathrm{~ms} /$ pix recorded between 5 and $200 \mathrm{mV} / \mathrm{s}$ for $\left[\mathrm{Ru}\left(\mathrm{NH}_{3}\right)_{6}\right]^{3+/ 2+}$, showing quasi-reversible reaction versus $\mathrm{Ag} / \mathrm{AgCl}$ reference electrode, evidenced by the monotonic increase/decrease of the oxidation/reduction peak current with square root of the scan rate (inset of Figure $7 \mathrm{~b}$ ). Equivalent CVs for all dwell times in the interval $30-120 \mathrm{~ms} /$ pix are showed in Figure S11. The average HET $\left(k_{0}\right)$ value calculated by the Nicholson method $^{36}$ over three $50 \mathrm{~ms} /$ pix electrodes was $0.0146 \pm 2.08$ $\mathrm{cm} / \mathrm{s}$, comparable to other $\mathrm{sp}^{2}$ carbon materials, such as graphene on a copper electrode $\left((15 \pm 2) \times 10^{-3} \mathrm{~cm} / \mathrm{s}\right)^{37}$ and Q-graphene $\left(18 \times 10^{-3} \mathrm{~cm} / \mathrm{s}\right){ }^{38}$ Favorable ET kinetic was found compared to other graphene materials such as monolayer graphene $\left(1.1 \times 10^{-3} \mathrm{~cm} / \mathrm{s}\right)$ and quasi-graphene $\left(1.6 \times 10^{-3} \mathrm{~cm} / \mathrm{s}\right)$ and graphite-based electrodes (edge plane pyrolytic graphite EPPG $=8.8 \times 10^{-3} \mathrm{~cm} / \mathrm{s}$ and basal plane pyrolytic graphite $\left.\mathrm{BPPG}=38 \times 10^{-3} \mathrm{~cm} / \mathrm{s}\right) .{ }^{39}$ This is interesting because $\left[\mathrm{Ru}\left(\mathrm{NH}_{3}\right)_{6}\right]^{3+/ 2+}$ being an outer sphere redox mediator is insensitive to the oxygen content and the surface structure, and only sensitive to the density of electronic states (DOS). This means that the reversible redox reaction of $\left[\mathrm{Ru}\left(\mathrm{NH}_{3}\right)_{6}\right]^{3+/ 2+}$ (i.e., rapid ET) on the LIG electrode must be supported by a sufficient DOS. This in turn can only be due to the increased DOS at the edges of graphene (compared to basal planes), resulting in a faster electrode kinetics and associated with the high $3 \mathrm{D}$ porous network rich in edge sites. The average HET $\left(k_{0}\right)$ value calculated for $\left[\mathrm{Fe}(\mathrm{CN})_{6}\right]^{3-/ 4-}$ by the Nicholson method over three electrodes was $(13 \pm 1) \times$ $10^{-3} \mathrm{~cm} / \mathrm{s}$ (data not shown), comparable with reported literature data of CVD-Gr and Q-graphene. ${ }^{14}$

Figure $7 \mathrm{c}$ shows $\mathrm{CVs}$ measured in $\left[\mathrm{Fe}(\mathrm{CN})_{6}\right]^{3-/ 4-}$ for three different electrodes, displaying good current reproducibility. In order to show practical applicability beyond standard redox mediators, Figure $7 \mathrm{~d}$ shows electrochemical detection of benzocaine, a local anesthetic, frequently used as additive in street samples of cocaine powder. ${ }^{40}$ The $\mathrm{CV}$ for $5 \mathrm{mM}$ aqueous solution of benzocaine measured in $0.1 \mathrm{M} \mathrm{KCl}$ supporting electrolyte at $\mathrm{pH} 2$ at $100 \mathrm{mV} / \mathrm{s}$ scan rate showed an oxidation peak at $0.386 \mathrm{mV}$ and a reduction peak at $0.352 \mathrm{mV}$ (vs $\mathrm{Ag}$ / $\mathrm{AgCl}$ ). Peak position and sensitivity were comparable to those obtained in literature for carbon screen printed macroscopic electrodes. ${ }^{40}$ Finally, square-wave voltammetry was performed to characterize the electrochemical behavior of LIG electrodes with benzocaine (inset Figure $7 \mathrm{~d}$ ). A scan from 0 to $0.6 \mathrm{~V}$ versus $\mathrm{Ag} / \mathrm{AgCl}$ was applied at a frequency of $100 \mathrm{~Hz}$, with an amplitude of $100 \mathrm{mV}$ and a step potential of $1 \mathrm{mV}$. All benzocaine measurements were performed using a portable potentiostat apparatus, in order to further show practical use and applicability.

\section{CONCLUSIONS}

LIG electrodes were fabricated on flexible polyimide sheets by direct laser irradiation with low cost visible laser engraving machines under ambient conditions. The morphological, structural, electrical, and electrochemical characteristics of LIGs obtained at different laser dwell times between 20 and $120 \mathrm{~ms} /$ pix were investigated. It was found that structures obtained at $40-50 \mathrm{~ms} /$ pix dwell times displayed 3D porous morphology, low sheet resistance, and graphenelike carbon spectral signatures. The electrochemical characterization performed with outer-sphere $\mathrm{Ru}\left(\mathrm{NH}_{3}\right)_{6}{ }^{3+/ 2+}$ and inner sphere $\mathrm{Fe}(\mathrm{CN})_{6}{ }^{3-/ 4-}$ redox mediators showed quasi-reversible ET at the LIG working electrode and fast ET kinetics with $k_{0}$ of $0.014 \mathrm{~cm} / \mathrm{s}$ calculated for $\mathrm{Ru}\left(\mathrm{NH}_{3}\right)_{6}{ }^{3+/ 2+}$ for $50 \mathrm{~ms} / \mathrm{pix}$ working electrodes. Practical usability of fabricated electrodes for low cost screening of analytes was demonstrated by the quasi-reversible ET showed with all carbon systems and by the proof-of-concept detection of benzocaine obtained by low cost, lightweight, and portable electrochemical readout instrumentation. These electrodes display great potential for low cost and 
disposable analysis and development of DIY flexible electrochemical platforms.

\section{EXPERIMENTAL SECTION}

Materials. Commercial polyimide films with a nominal thickness of $80 \mu \mathrm{m}$ were purchased from Radionics and used without further treatment. Hexaammineruthenium(III) chloride, potassium hexacyanoferrate(III), potassium chloride, and benzocaine were purchased from Sigma-Aldrich and used without further purification. Milli-Q water (resistivity $18 \mathrm{M} \Omega$ $\mathrm{cm}$ ) was used throughout the experiments.

Electrode Fabrication. LIG electrodes were fabricated using a mini-speed laser engraving machine (Colemeter DK-8 Pro-5 Square Haste Edition) equipped with a diode laser with a wavelength of $405 \mathrm{~nm}$. Polyimide tapes fixed on glass microscope slides for support were irradiated at $500 \mathrm{~mW}$ laser power and dwell times (dwell times) between 10 and $120 \mathrm{~ms} /$ pix. LIG electrode structures designed in Microsoft PowerPoint were fabricated by raster scanning of the laser beam to create the electrode pattern on the polyimide surface. Fabricated electrodes were washed with acetone and isopropanol and dried with a $\mathrm{N}_{2}$ gun before use.

Characterization. LIG electrodes were morphologically characterized by using a cold-cathode field-emission scanning electron microscope (SEM, JSM-7500F, JEOL UK Ltd.), operating at $5 \mathrm{kV}$ acceleration voltage. White light optical microscopy images of fabricated LIG electrodes were acquired using an Axioskop II, Carl Zeiss Ltd. Microscope interfaced to a charge-coupled detector camera (Coolsnap CF, Photometrics). LIG height measurements were acquired using a KLA-Tencor p17 profilometer with stylus weight of $2 \mathrm{mg}$ and resolution of $4 \mu \mathrm{m}$.

Surface wettability was measured by using a Dataphysics OCA 20 Wetting angle system in air at ambient temperature by dropping distilled water droplets ( $1 \mathrm{~mm}$ diameter) on the LIG surfaces. The average CA value was acquired by measuring at three different positions of the same sample.

Two-terminal current-voltage measurements $( \pm 1 \mathrm{~V}, 10 \mathrm{mV}$ step) were obtained under ambient conditions on transmission line method (TLM) structures using an Agilent E5270B parameter analyzer interfaced to a LakeShore Desert TTPX probe station. For these TLM structures, arrays of LIG tracks were written at different dwell times, ranging from 20 to 120 $\mathrm{ms} /$ pix. Each track had $\sim 1 \mathrm{~mm}$ square LIG pads for electrical probing. Each TLM structure comprised four collinear tracks separated by contact pads, allowing measurement of resistance for four values of track length for each device $\left(L_{1}=225 \mu \mathrm{m}, L_{2}\right.$ $=1335 \mu \mathrm{m}, L_{3}=1920 \mu \mathrm{m}$, and $\left.L_{4}=2780 \mu \mathrm{m}\right)$. The track resistance $R_{\mathrm{i}}$ between two consecutive pads could then be related to the track length $\left(L_{\mathrm{i}}\right)$ via

$$
R_{\mathrm{i}}=R_{\mathrm{c}}+\left(R_{\mathrm{s}} \times L_{\mathrm{i}}\right) / W
$$

where $R_{c}$ is the contact resistance, $R_{\mathrm{s}}$ is the sheet resistance of the sample, and $W$ is the track width. Values for $R_{\mathrm{s}}$ and $R_{\mathrm{c}}$ were thus obtained from linear regression of $R_{\mathrm{i}}$ versus $L_{\mathrm{i}}$.

Raman measurements were performed using a Renishaw inVia Raman system equipped with a $514 \mathrm{~nm}$ helium-neon laser. The laser beam was focused onto the sample through a Leica $20 \times$ objective with 0.4 NA. Acquisition time was usually $10 \mathrm{~s}$ and measured power was $3 \mathrm{~mW}$.

XPS measurements were carried out in an ultrahigh vacuum chamber with a base pressure $\sim 5 \times 10^{-10}$ mbar equipped with a SPECS LHS-10 hemispherical electron analyzer and a dual anode $\mathrm{Al} / \mathrm{Mg} \mathrm{X}$-ray gun. All XPS measurements were acquired using the unmonochromatized $\mathrm{Mg} \mathrm{K} \alpha$ line at $1253.6 \mathrm{eV}$ and an analyzer pass energy of $36 \mathrm{eV}$, giving a fwhm of $0.9 \mathrm{eV}$ for the $\mathrm{Au} 4 \mathrm{f}_{7 / 2}$ peak. The XPS core level spectra were analyzed by fitting each total spectrum to a series of individual mixed Gaussian-Lorentzian peaks, following a Shirley background subtraction.

Electrochemical measurements were performed with a CHI760 bi-potentiostat electrochemical system using a Pt wire as the counter electrode, $\mathrm{Ag} / \mathrm{AgCl}$ as the reference electrode, and LIG as the working electrode. The three electrodes were assembled in a Teflon cell (see Figure S8 for details) with a circular area of $8 \mathrm{~mm}$ diameter exposed to the electrolyte. $\mathrm{CV}$ experiments were performed in aqueous solution using inner-sphere $\left(\left[\mathrm{Fe}(\mathrm{CN})_{6}\right]^{3-/ 4-}\right)$ and outersphere $\left(\left[\mathrm{Ru}\left(\mathrm{NH}_{3}\right)_{6}\right]^{3+/ 2+}\right)$ redox mediators at a concentration of 5 $\mathrm{mM}$ dissolved in $0.1 \mathrm{M} \mathrm{KCl}$. Solutions were purged with $\mathrm{N}_{2}$ for 30 min prior to measurements and during measurements. HET rate constants were determined from the anodic peak separation using the method of Nicholson ${ }^{32}$ by assuming the transfer coefficient $\alpha=0.5$ and using the following diffusion coefficient $D=6.5 \times 10^{-6} \mathrm{~cm}^{2} \mathrm{~s}^{-1}$ for $\left[\mathrm{Ru}\left(\mathrm{NH}_{3}\right)_{6}\right]^{3+/ 2+}$. Benzocaine electrochemical characterization was carried out with an EmStatBlue (Palmsens) portable potentiostat at a benzocaine concentration of $5 \mathrm{mM}$ dissolved in $0.1 \mathrm{M} \mathrm{KCl}$.

\section{ASSOCIATED CONTENT}

\section{Supporting Information}

The Supporting Information is available free of charge at https://pubs.acs.org/doi/10.1021/acsomega.9b03418.

LIG optical microscopy images taken at each dwell time; SEM images taken at each dwell time; determination of surface area; CA data; Raman analysis details; XPS analysis details; electrochemical set-up, and CV data (PDF)

\section{AUTHOR INFORMATION}

\section{Corresponding Author}

Daniela Iacopino - University College Cork, Cork, Ireland; ๑ orcid.org/0000-0003-2301-9401; Email: daniela.iacopino@tyndall.ie

\section{Other Authors}

Micheal Burke - University College Cork, Cork, Ireland; (1) orcid.org/0000-0003-1831-8829

Cathal Larrigy - University College Cork, Cork, Ireland Eoghan Vaughan - University College Cork, Cork, Ireland

George Paterakis - Foundation for Research and Technology-Hellas (FORTH/ICE-HT), Patras, Greece

Labrini Sygellou - Foundation for Research and Technology-Hellas (FORTH/ICE-HT), Patras, Greece

Aidan J. Quinn - University College Cork, Cork, Ireland; (1) orcid.org/0000-0003-4021-9990

Grégoire Herzog - LCPME, CNRS-Université de Lorraine, Villers-Tes-Nancy, France; (1) orcid.org/00000003-1932-9300

Costas Galiotis - University of Patras, Patras, Greece; (1) orcid.org/0000-0001-8079-5488

Complete contact information is available at: 
https://pubs.acs.org/10.1021/acsomega.9b03418

\section{Author Contributions}

M.B. and C.L. contributed equally to the realization of the manuscript. The manuscript was written through contributions of all authors. All authors have given approval to the final version of the manuscript.

\section{Notes}

The authors declare no competing financial interest.

\section{ACKNOWLEDGMENTS}

This publication has emanated from research conducted with the financial support of the European Union H2020 project Apache (814496) project and Science Foundation Ireland (SFI) under grant number SFI 16/RC/3918 (CONFIRM), 13/RC/2077 (CONNECT) and SFI TIDA 5118, cofunded by the European Regional Development Fund.

\section{REFERENCES}

(1) McCreery, R. L. Advanced Carbon Electrode Materials for Molecular Electrochemistry. Carbon 2008, 108, 2646-2687.

(2) Unwin, P. R.; Güell, A. G.; Zhang, G. Nanoscale Electrochemistry of $\mathrm{sp}^{2}$ Carbon Materials: from Graphite and Graphene to Carbon Nanotubes. Acc. Chem. Res. 2016, 49, 2041-2048.

(3) Chen, D.; Feng, H.; Li, J. Graphene Oxide: Preparation, Functionalization, and Electrochemical Applications. Chem. Rev. 2012, 112, 6027-6053.

(4) Wu, Z.-S.; Sun, Y.; Tan, Y.-Z.; Yang, S.; Feng, X.; Müllen, K. Three-Dimensional Graphene-Based Macro- and Mesoporous Frameworks for High-Performance Electrochemical Capacitive Energy Storage. J. Am. Chem. Soc. 2012, 134, 19532-19535.

(5) Wu, M.; Meng, S.; Wang, Q.; Si, W.; Huang, W.; Dong, X. Nickel-Cobalt Oxide Decorated Three-Dimensional Graphene as an Enzyme Mimic for Glucose and Calcium Detection. ACS Appl. Mater. Interfaces 2015, 7, 21089-21094.

(6) Chen, Z.; Ren, W.; Gao, L.; Liu, B.; Pei, S.; Cheng, H.-M. ThreeDimensional Flexible and Conductive Interconnected Graphene Networks Grown by Chemical Vapour Deposition. Nat. Mater. 2011, 10, 424-428.

(7) Borini, S.; White, R.; Wei, D.; Astley, M.; Haque, S.; Spigone, E.; Harris, N.; Kivioja, J.; Ryhänen, T. Ultrafast Graphene Oxide Humidity Sensors. ACS Nano 2013, 7, 11166-11173.

(8) Amal Raj, M.; Abraham John, S. Fabrication of Electrochemically Reduced Graphene Oxide Films on Glassy Carbon Electrode by SelfAssembly Method and Their Electrocatalytic Application. J. Phys. Chem. C 2013, 117, 4326-4335.

(9) Lawes, S.; Riese, A.; Sun, Q.; Cheng, N.; Sun, X. Printing Nanostructured Carbon for Energy Storage and Conversion Applications. Carbon 2015, 92, 150-176.

(10) Lin, J.; Peng, Z.; Liu, Y.; Ruiz-Zepeda, F.; Ye, R.; Samuel, E. L. G.; Yacaman, M. J.; Yacobson, B. I.; Tour, J. M. Laser-Induced Porous Graphene Films from Commercial Polymers. Nat. Commun. 2014, 5, 5714.

(11) Chyan, Y.; Ye, R.; Li, Y.; Singh, S. P.; Arnusch, C. J.; Tour, J. M. Laser-Induced Graphene by Multiple Lasing: Towards Electronics on Cloth, Paper, and Food. ACS Nano 2018, 12, 2176-2183.

(12) Li, L.; Zhang, J.; Peng, Z.; Li, Y.; Gao, C.; Ji, Y.; Ye, R.; Kim, N. D.; Zhong, Q.; Yang, Y.; Fei, H.; Ruan, G.; Tour, J. M. HighPerformance Pseudocapacitive Microsupercapacitors from LaserInduced Graphene. Adv. Mater. 2016, 28, 838-845.

(13) Ye, R.; James, D. K.; Tour, J. M. Laser-Induced Graphene: From Discovery to Translation. Adv. Mater. 2019, 31, 1803621.

(14) Nayak, P.; Kurra, N.; Xia, C.; Alshareef, H. N. Highly Efficient Laser Scribed Electrodes for on-Chip Electrochemical Sensing Applications. Adv. Electron. Mater. 2016, 2, 1600185.
(15) Zhang, C.; Xie, Y.; Zhang, C.; Lin, J. Upgrading coal to multifunctional graphene based materials by direct laser scribing. Carbon 2019, 153, 585-591.

(16) Fenzl, C.; Nayak, P.; Hirsch, T.; Wolfbeis, O. S.; Alshareef, H. N.; Baeumner, A. J. Laser-Scribed Graphene Electrodes for AptamerBased Biosensing. ACS Sens. 2017, 2, 616-620.

(17) Cardoso, A. R.; Marques, A. C.; Santos, L.; Carvalho, A. F.; Costa, F. M.; Martins, R.; Sales, M. G. F.; Fortunato, E.; Fortunato, E. Molecularly-Imprinted Chloramphenicol Sensor with Laser-Induced Graphene Electrodes. Biosens. Bioelectron. 2019, 124-125, 167-175.

(18) Zhang, Z.; Song, M.; Hao, J.; Wu, K.; Li, C.; Hu, C. Visible light laser-induced graphene from phenolic resin: A new approach for directly writing graphene-based electrochemical devices on various substrates. Carbon 2108, 127, 287-296.

(19) Cai, J.; Lv, C.; Watanabe, A. Laser direct writing of highperformance flexible all-solid-state carbon micro-supercapacitors for an on-chip self-powered photodetection system. Nano Energy 2016, 30, 790-800.

(20) Vanegas, D.; Patiño, L.; Mendez, C.; Oliveira, D.; Torres, A.; Gomes, C.; McLamore, E. Laser Scribed Graphene Biosensor for Detection of Biogenic Amines in Food Samples Using Locally Sourced Materials. Biosensors 2018, 8, 42-61.

(21) Romero, F.; Salinas-Castillo, A.; Rivadeneyra, A.; Albrecht, A.; Godoy, A.; Morales, D.; Rodriguez, N. In-Depth Study of Laser Diode Ablation of Kapton Polyimide for Flexible Conductive Substrates. Nanomaterials 2018, 8, 517-528.

(22) Dong, Y.; Rismiller, S. C.; Lin, J. Molecular Dynamic Simulation of Layered Graphene Clusters Formation from Polyimides under Extreme Conditions. Carbon 2016, 104, 47-55.

(23) Luo, S.; Hoang, P. T.; Liu, T. Direct Laser Writing for Creating Porous Graphitic Structures and their Use for Flexible and Highly Sensitive Sensor and Sensor Arrays. Carbon 2016, 96, 522-531.

(24) Li, Y.; Luong, D. X.; Zhang, J.; Tarkunde, Y. R.; Kittrell, C.; Sargunaraj, F.; Ji, Y.; Arnusch, C. J.; Tour, J. M. Laser-Induced Graphene in Controlled Atmospheres: From Superhydrophilic to Superhydrophobic Surfaces. Adv. Mater. 2017, 29, 1700496.

(25) Zhou, Y.; Wang, B.; Song, X.; Li, E.; Li, G.; Zhao, S.; Yan, H. Control Over the Wettability of Amorphous Carbon in a Large Range from Hydrophilicity to Super-hydrophobicity. Appl. Surf. Sci. 2006, 253, 2690-2694.

(26) Banerjee, D.; Mukherjee, S.; Chattopadhyay, K. K. Controlling the Surface Topology and Hence the Hydrophilicity of Amorphous Carbon Thin Films. Carbon 2010, 48, 1025-1031.

(27) Wei, Y.; Jia, C. Q. Intrinsic Wettability of Graphitic Carbon. Carbon 2015, 87, 10-17.

(28) Kim, K. S.; Zhao, Y.; Jang, H.; Lee, S. Y.; Kim, J. M.; Kim, K. S.; Ahn, J.-H.; Kim, P.; Choi, J.-Y.; Hong, B. H. Large-Scale Pattern Growth of Graphene Films for Stretchable Transparent Electrodes. Nature 2009, 457, 706-710.

(29) Li, X.; Zhu, Y.; Cai, W.; Borysiak, M.; Han, B.; Chen, D.; Piner, R. D.; Colombo, L.; Ruoff, R. S. Transfer of Large-Area Graphene Films for High-Performance Transparent Conductive Electrodes. Nano Lett. 2009, 9, 4359-4363.

(30) Romero, F. J.; Rivadeneyra, A.; Toral, V.; Castillo, E.; GarcíaRuiz, F.; Morales, D. P.; Rodriguez, N. Design Guidelines of Laser Reduced Graphene Oxide Conformal Thermistor for IoT Applications. Sens. Actuators, A 2018, 274, 148-154.

(31) Das, S. R.; Nian, Q.; Cargill, A. A.; Hondred, J. A.; Ding, S.; Saei, M.; Cheng, G. J.; Claussen, J. C. 3D Nanostructured inkjet Printed Graphene via UV-pulsed Laser Irradiation Enables PaperBased Electronics and Electrochemical Devices. Nanoscale 2016, 8, 15870-15879.

(32) Ferrari, A. C.; Robertson, J. Interpretation of Raman Spectra of Disordered and Amorphous Carbon. Phys. Rev. B: Condens. Matter Mater. Phys. 2000, 61, 14095.

(33) Ferrari, A. C.; Basko, D. M. Raman Spectroscopy as a Versatile Tool for Studying the Properties of Graphene. Nat. Nanotechnol. 2013, 8, 235-246. 
(34) Tuinstra, F.; Koenig, J. L. Raman Spectrum of Graphite. J. Chem. Phys. 1970, 53, 1126-1130.

(35) Lespade, P.; Al-Jishi, R.; Dresselhaus, M. S. Model for Raman Scattering from Incompletely Graphitized Carbons. Carbon 1982, 20, 427-431.

(36) Nicholson, R. S. Theory and Application of Cyclic Voltammetry for Measurement of Electrode Reaction Kinetics. Anal. Chem. 1965, 37, 1351-1355.

(37) Bosch-Navarro, C.; Laker, Z. P.; Rourke, J. P.; Wilson, N. R. Reproducible, Stable and Fast Electrochemical Activity from Easy to Make Graphene on Copper Electrodes. Phys. Chem. Chem. Phys. 2015, 17, 29628-29636.

(38) Randviir, E. P.; Brownson, D. A. C.; Gómez-Mingot, M.; Kampouris, D. K.; Iniesta, J.; Banks, C. E. Electrochemistry of QGraphene. Nanoscale 2012, 4, 6470-6480.

(39) Brownson, D. A. C.; Varey, S. A.; Hussain, F.; Haigh, S. J.; Banks, C. E. Electrochemical Properties of CVD Grown Pristine Graphene: Monolayer-vs. Quasi-Graphene. Nanoscale 2014, 6, 16071621.

(40) Komorsky-Lovrić, S.; Vukašinović, N.; Penovski, R. Voltammetric Determination of Microparticles of Some Local Anesthetics and Antithusics Immobilized on the Graphite Electrode. Electroanalysis 2003, 15, 544-547. 